\title{
Epidemiological Markers in Adult Glial Tumors: A Single-Center Experience and The Utility of the Classification System
}

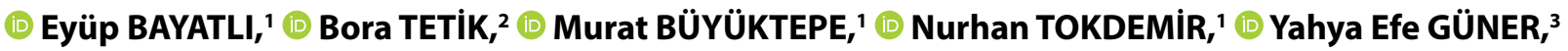 \\ (D) Yıldız GÜNEY, ${ }^{4}$ (i) Hasan Çağlar UĞUR'
}

'Deparment of Neurosurgery, Ankara University Faculty of Medicine, Ankara-Turkey

${ }^{2}$ Deparment of Neurosurgery, Inonu University Faculty of Medicine, Malatya-Turkey

${ }^{3}$ Deparment of Neurosurgery, Yuksek İhtisas University Faculty of Medicine, Ankara-Turkey

${ }^{4}$ Deparment of Radiation Oncology, Yüksek Ihtisas University, Ankara Memorial Hospital, Ankara-Turkey

\section{OBJECTIVE}

This study aimed to investigate the etiology of gliomas and determine the utility of the World Health Organization (WHO) classification of central nervous system tumors.

\section{METHODS}

Patients aged $\geq 18$ years who underwent surgery or were followed up for glial tumors between January 2017 and January 2020 and whose pathology reports indicated grade II-IV gliomas were included in the study. Patients with missing data, pathology results incompatible with grade II-IV gliomas, and unavailable standard molecular/genetic tumor profiles were excluded from the study.

\section{RESULTS}

The results of the standard histopathological and molecular/genetic analyses were evaluated retrospectively without any additional examinations. Data from 259 patients were evaluated. Of these, 8 patients who did not meet the criteria for glioma pathology and 27 patients with not otherwise specified molecular pathological examination results were excluded from the study. Patients were evaluated in detail regarding demographic and admission data, pathology analysis, potential risk factors, and survival results.

\section{CONCLUSION}

Many factors, particularly high blood glucose levels, sedentary lifestyle, and radiofrequency electromagnetic field exposure, appear to have a relationship with glioma etiology. There is a major heterogeneity and lack of standardized efficient laboratory procedures that may interfere with reliable standard molecular results. "False positive" molecular markers consist a major classification issue and methods that reflect the requirements of the WHO classification may themselves be inadequate to establish a profile with adequate sensitivity. The development of more practical and accessible methods in addition to standardized, rapid, and reliable methods for testing multiple markers at an acceptable cost is urgently needed.

Keywords: Classification; epidemiology; glioma; molecular; tumor. Copyright $\odot$ 2022, Turkish Society for Radiation Oncology 


\section{Introduction}

Primary central nervous system (CNS) tumors remain a serious health problem due to their high mortality and morbidity rates. The overall incidence of primary malignant brain and CNS tumors covering all ages has been reported to be 7.27/100,000 individuals.[1] Although an understanding of the molecular and genetic profiles of such tumors has increased recently, their etiology has remained largely unknown.

Molecular and genetic studies have opened new perspectives on the oncogenesis and prognosis of tumors. In 2016, the World Health Organization (WHO) changed the classification for CNS tumors and proposed a multilayer diagnostic model that integrated molecular markers with classical histopathological features.[2] Furthermore, the latest 2021 WHO classification has reflected the evolution and may be the future of CNS tumor classification. [3] However, the feasibility of such classification within laboratories with limited funding and equipment may be doubtful.

This study aimed to investigate the etiology of gliomas and determine the utility of the WHO classification of CNS tumors.

\section{Materials and Methods}

This study was conducted at Ankara University Faculty of Medicine, Department of Neurosurgery, Neuro-oncology Laboratory. Patients aged $\geq 18$ years who underwent surgery or were followed up for glial tumors between January 2017 and January 2020 and whose pathology reports indicated grade II-IV gliomas were included in the study.

The study protocol was approved by the Ethics Committee of Ankara University (Report No: İ6-301-19). Patients with missing data, pathology results incompatible with grade II-IV gliomas, and unavailable standard molecular/genetic tumor profiles were excluded from the study. Those who could not be characterized according to 2016 WHO classification (not otherwise specified [NOS]) were also excluded from the study.

Apart from known risk factors in literature, a data form was prepared to collect and evaluate as many factors as possible. This form was completed using data obtained from medical records, telephone calls, and follow-up visits by the same person (N.T.).

The results of the standard histopathological and molecular/genetic analyses were evaluated retrospectively without any additional examinations. Immuno- histochemical methods were used for the evaluation of isocitrate dehydrogenase (IDH), alpha-thalassemia Xlinked mental retardation (ATRX), and p53. The presence of $1 \mathrm{p} / 19 \mathrm{q}$ deletion was evaluated and interpreted using florescence in situ hybridization (FISH) as per the 2011 Euro-CNS guidelines. Real-time polymerase chain reaction (PCR) was used as much as possible in cases where immunohistochemical methods failed to obtain data regarding IDH1 and ATRX mutations.

The Shapiro-Wilk test was used to analyze the normality of data distribution. Student's t-test was used to compare normally distributed continuous data between two independent groups, whereas one-way analysis of variance was used to compare more than two groups. Tukey's test was used to test differences for significance, whereas the Mann-Whitney $U$ test was used to compare non-normally distributed data between two independent groups. Multiple groups were compared using the Kruskal-Wallis multiple comparison test. The Chi-square and Fisher's exact tests were used to compare nominal variables (cross tables) according to independent groups (diagnosis, grade, and others). Survival times were analyzed using the Kaplan-Meier analysis and log-rank tests. All statistical analyses were performed using IBM SPSS Statistics 20 software, with $\mathrm{p}<0.05$ indicating statistical significance.

\section{Results}

At the end of the planned study period, data from 259 patients were evaluated. Of these, 8 patients who did not meet the criteria for glioma pathology and $27 \mathrm{pa}-$ tients with NOS molecular pathological examination results were excluded from the study. Hence, descriptive and comparative statistical analyses were ultimately performed for 224 patients. Among the biomarkers, IDH, 1p/19q, ATRX, and p53 mutations had been evaluated. To facilitate the statistical processing of comparative data, final diagnoses were classified into five diagnostic groups: (1) Oligo (IDH mutant [IDHm], 1p/19q codeleted, oligodendroglioma); (2) Ast (IDHm, 1p/19q intact, astrocytoma); (3) AW (IDH wildtype [IDHwt] astrocytoma); (4) Gbm (IDHm glioblastome multiforme); and (5) GbmW (IDHwt glioblastome multiforme). Additional comparisons were made separately based on disease grade (II-IV).

\section{Demographic and Admission Data}

The study population had a mean age of 49.4 years $( \pm 15.7$; median $50.5[18-84])$ and comprised 84 


\begin{tabular}{|c|c|c|c|c|}
\hline \multirow[t]{2}{*}{ Tab } & \multicolumn{4}{|c|}{$\begin{array}{l}\text { Detailed data regarding family history of ma- } \\
\text { lignancy, educational status, income level, daily } \\
\text { sports habits, and blood group distribution of } \\
\text { the patients }\end{array}$} \\
\hline & & $\mathbf{n}$ & $\%$ & $\mathbf{p}$ \\
\hline \multicolumn{5}{|c|}{ Family history of malignancy } \\
\hline None & & 135 & 60.3 & \multirow[t]{4}{*}{$>0.05$} \\
\hline $1^{\text {st }} \mathrm{D \epsilon}$ & ree & 62 & 27.7 & \\
\hline $2^{\text {nd }} D$ & gree & 24 & 10.7 & \\
\hline $3^{\text {rd }} \mathrm{D}$ & yree & 3 & 1.3 & \\
\hline \multicolumn{5}{|c|}{ Educational status } \\
\hline Unle & ered & 15 & 6.7 & \multirow[t]{4}{*}{$>0.05$} \\
\hline Prim & y School & 108 & 48.2 & \\
\hline High & chool & 50 & 22.3 & \\
\hline Colle & & 51 & 22.8 & \\
\hline \multicolumn{5}{|c|}{ Income level } \\
\hline Low I & come & 113 & 50.4 & \multirow[t]{3}{*}{$>0.05$} \\
\hline Midd & Income & 109 & 48.7 & \\
\hline High & come & 2 & 0.9 & \\
\hline \multicolumn{5}{|c|}{ Daily sports habits } \\
\hline Rare & & 142 & 63.4 & \multirow[t]{3}{*}{$<0.05$} \\
\hline Interr & ittant & 67 & 29.9 & \\
\hline Frequ & & 15 & 6.7 & \\
\hline \multicolumn{5}{|c|}{ Blood group distribution } \\
\hline $\mathrm{ORH}$ & & 10 & 4.5 & \multirow[t]{8}{*}{$>0.05$} \\
\hline $\mathrm{ORH}$ & & 75 & 33.5 & \\
\hline $\mathrm{ARH}$ & & 7 & 3.1 & \\
\hline $\mathrm{ARH}$ & & 78 & 34.8 & \\
\hline $\mathrm{BRH}$ & & 6 & 2.7 & \\
\hline $\mathrm{BRH}$ & & 29 & 12.9 & \\
\hline$A B R$ & $(-)$ & 2 & 0.9 & \\
\hline $\mathrm{AB} R$ & & 17 & 7.6 & \\
\hline
\end{tabular}

(37.5\%) females and 140 (62.5\%) males. A comparison among the diagnostic groups showed that the GbmW group was significantly older than the Oligo $(\mathrm{p}<0.001)$, Ast $(\mathrm{p}<0.001)$, and Gbm $(\mathrm{p}<0.05)$ groups. However, no significant difference in gender $(\mathrm{p}=0.383)$ was ob- served among the diagnostic groups. Meanwhile, no difference in age $(\mathrm{p}=0.777)$ was observed among those with grade II-III disease. However, those with grade IV disease were significantly older $(\mathrm{p}=0.000)$.

Similar rates of admission symptoms were noted: Headache (34.8\%), epileptic seizure (34.8\%), motor deficit (23.2\%), and cranial nerve deficit (7.1\%), with no significant differences $(\mathrm{p}=0.120)$.

Among the included patients, $84.8 \%$ and $15.2 \%$ were married and single, respectively. Differences regarding the family history of malignancy, educational status, and income level were found to be statistically insignificant $(\mathrm{p}=0.105)$ and are presented in Table 1.

Given the heterogenous distribution of patients as per blood groups, general analysis could not be performed. However, no significant differences in the ABO system $(\mathrm{p}=0.718)$ and $\mathrm{RH}$ system $(\mathrm{p}=0.966)$ were observed separately (Table 1).

The diagnostic groups were categorized according to chronic diseases (diabetes mellitus, hypertension, and both [metabolic]), allergic diseases (hay fever, atopy, asthma, urticaria, and others), and inflammatory diseases (rheumatic disease, psoriasis, goiter, and others). No significant differences in chronic, allergic, and inflammatory diseases were found. A separate survey, however, noted that $16.1 \%$ of the patients were hyperglycemic before diagnosis. Further analysis showed that the GbmW group had significantly higher blood glucose levels than the Oligo $(\mathrm{p}=0.001)$ and Ast $(\mathrm{p}=0.011)$ groups before diagnosis. Likewise, those diagnosed with grade IV tumors had significantly higher blood sugar levels before diagnosis than those diagnosed with grade II and III tumors (Table 2).

\section{Potential Risk Factors}

Stress load and daily sleep time were determined using the visual analog scale (1-10 scale). Patients had a

Table 2 Distribution of chronic diseases among the diagnostic groups

\begin{tabular}{|c|c|c|c|c|c|c|c|}
\hline & $\begin{array}{c}\text { None } \\
(\%)\end{array}$ & $\begin{array}{l}\text { Diabetes } \\
\text { alone (\%) }\end{array}$ & $\begin{array}{c}\text { HT alone } \\
\text { (\%) }\end{array}$ & $\begin{array}{c}\text { Allergic } \\
\text { diseases } \\
(\%)\end{array}$ & $\begin{array}{l}\text { Inflammatory } \\
\text { disease } \\
(\%)\end{array}$ & $\begin{array}{c}\text { Metabolic } \\
\text { (D+HT) } \\
(\%)\end{array}$ & Total \\
\hline IDHm, 1p/19q codeleted, oligodendroglioma & $33(82.5)$ & $2(5)$ & $1(2.5)$ & $1(2.5)$ & $3(7.5)$ & 0 & $40(100)$ \\
\hline IDHm, 1p/19q intact, astrocytoma & $34(81)$ & $2(4.8)$ & $2(4.8)$ & $1(2.4)$ & $3(7.1)$ & 0 & $42(100)$ \\
\hline IDHwt astrocytoma & $4(36.4)$ & 0 & $3(27.3)$ & 0 & $1(9.1)$ & $3(27.3)$ & $11(100)$ \\
\hline IDHm GBM & $14(73.7)$ & $2(10.5)$ & $3(15.8)$ & 0 & 0 & 0 & $19(100)$ \\
\hline IDHwt GBM & $68(60.7)$ & $8(7.1)$ & $16(14.3)$ & $5(4.5)$ & $1(0.9)$ & $14(12.5)$ & $112(100)$ \\
\hline Total & $153(68.3)$ & $14(6.3)$ & $25(11.2)$ & $7(3.1)$ & $8(3.6)$ & $17(7.6)$ & $224(100)$ \\
\hline
\end{tabular}

D: Diabetes; HT: Arterial hypertension; IDHm: IDH mutant; IDHwt: IDH wildtype; GBM: Glioblastoma 


\begin{tabular}{|c|c|c|c|c|}
\hline \multirow[t]{2}{*}{ Table 3} & \multicolumn{4}{|c|}{$\begin{array}{l}\text { istribution of tumor localization and lateral- } \\
\text { zation }\end{array}$} \\
\hline & $\mathbf{n}$ & $\%$ & Right & Left \\
\hline Frontal & 80 & 35.7 & 34 & 46 \\
\hline Fronto-parietal & 21 & 9.4 & 8 & 13 \\
\hline Fronto-temporal & 10 & 4.5 & 5 & 5 \\
\hline Occipital & 2 & 0.9 & 0 & 2 \\
\hline Parietal & 35 & 15.6 & 17 & 18 \\
\hline Parieto-occipital & 13 & 5.8 & 9 & 4 \\
\hline Temporal & 50 & 22.3 & 25 & 25 \\
\hline Temporo-parietal & 9 & 4 & 5 & 4 \\
\hline Midline & 4 & 1.8 & 3 & 1 \\
\hline Total & 224 & 100 & 106 & 118 \\
\hline
\end{tabular}

mean stress score of $6.3( \pm 1.4$; median 6 [1-10]) and daily sleep time of $6.9( \pm 1.5$; median 7 [2-15]) h. However, no significant differences in both factors were noted among the diagnostic groups as well as the grade groups ( $\mathrm{p}=0.846$ and 0.580 , respectively).

Analysis was achieved for data obtained regarding anthropometric parameters and sports habits. Mean height $(\mathrm{m})$, weight $(\mathrm{kg})$, and body mass index (BMI) $\left(\mathrm{kg} / \mathrm{m}^{2}\right)$ were $1.69 \mathrm{~m}, 76.5 \mathrm{~kg}$ and $26.9 \mathrm{~kg} / \mathrm{m}^{2}$, respectively. No significant difference in BMI was noted among the diagnostic groups $(\mathrm{p}=0.166)$. However, patients with grade IV tumors had a significantly higher BMI than those with grade II tumors $(p=0.037)$. Moreover, the Ast group was taller than the Gbm group $(\mathrm{p}=0.003)$. Data on daily sports habits showed that the Gbm and GbmW groups engaged in significantly lesser sports activities than the Ast and Oligo groups ( $\mathrm{p}<0.01)$.

Majority $(82.3 \%)$ of patients reported a balanced diet. However, no statistical comparison was made for this parameter. Nearly, half of the patients (49.1\%) used daily sweeteners, with no significant difference among the diagnostic groups $(\mathrm{p}=0.866)$ and grade groups $(\mathrm{p}=0.093)$. Among the included patients, $19(8.5 \%)$ reported frequent, 91 (40.6\%) reported intermittent, and 114 (50.9\%) reported rare over-the-counter drug usage $(\mathrm{p}=0.156)$. The average seafood and alcohol consumption were $1.5( \pm 1.3)$ and $0.3( \pm 0.7)$ times per month, respectively $(\mathrm{p}=0.191)$. Our results determined that $57.6 \%, 33.5 \%$, and $8.9 \%$ of the patients drank bottled water, main water, and purified water, respectively, with no significant difference among the groups.

Our data showed that $33 \%$ of the study patients were smokers. However, no significant difference in smoking rates was observed among the diagnostic groups $(\mathrm{p}=0.134)$. Daily tea and coffee consumption were $4.6( \pm 2)$ and $1.5( \pm 1)$ cups, respectively $(\mathrm{p}>0.05)$.
Mean cumulative and daily mobile phone usage was 11.5 ( \pm 6.2 ; median 10 [0-25]) years and 64.9 ( \pm 80.2 ; median 30 [0-600]) min, respectively. Overall, the GbmW group had a lower mobile phone cumulative use than the Oligo and Ast groups. No significant difference in daily usage was observed among the diagnostic groups $(\mathrm{p}=0.058)$. However, those with grade II and III tumors had a longer cumulative exposure time than those with grade IV tumors $(\mathrm{p}<0.05)$. Moreover, those with grade II tumors had a significantly more daily usage compared with those with grade III and IV tumors $(\mathrm{p}<0.01)$.

\section{Pathology Analysis}

Our findings showed that $47.3 \%$ and $52.7 \%$ of the patients had right- and left-side tumor lateralization, respectively. However, no significant differences in tumor lateralization and localization were found among the diagnostic groups $(p=0.150)$ and grade $(p=0.848)$ groups. Moreover, no significant relationship was found between tumor lateralization and IDH $(\mathrm{p}=0.956)$ and p53 mutation $(\mathrm{p}=0.297)$. However, left-sided tumors had significantly higher ATRX mutations $(\mathrm{p}=0.016)$, whereas right-sided tumors had a significantly higher $1 \mathrm{p} / 19 \mathrm{q}$ codeletion ( $\mathrm{p}=0.034$ ) (Table 3 ).

The Kruskal-Wallis multiple comparison analysis showed no significant difference in IDH mutations among the Oligo, Ast, and Gbm groups ( $\mathrm{p}>0.05$ ). However, those with grade IV disease had significantly lower IDH mutations than those with Grade II ( $\mathrm{p}=0.000)$ and III $(\mathrm{p}=0.000)$ disease. IDHm cases were found to be significantly younger $(\mathrm{p}=0.000)$.

No significant difference in $1 \mathrm{p} / 19 \mathrm{q}$ codeletion was observed between grade II and III tumors $(\mathrm{p}=0.812)$. ATRX mutation frequency was significantly higher in the Ast group than in the Oligo $(\mathrm{p}=0.000)$ and $\mathrm{Gbm}$ $(\mathrm{p}=0.000)$ groups; higher in the Gbm group than in the Oligo group ( $\mathrm{p}=0.000)$; and higher in the AW group than in the Oligo group ( $\mathrm{p}=0.027)$. The Gbm group had a significantly higher ATRX mutation frequency than the $\mathrm{GbmW}$ group ( $\mathrm{p}=0.000$ ) but a significantly lower frequency than the AW group $(\mathrm{p}=0.010)$. Patients with grade II tumors had significantly higher ATRX mutation frequencies than those with grade IV tumors $(p=0.001)$. Furthermore, analysis showed that P53 mutation rates were significantly higher in the Ast group than in the Oligo $(\mathrm{p}=0.000)$ and $\mathrm{GbmW}$ $(p=0.006)$ groups and higher in the Gbm group than in the Oligo group $(\mathrm{p}=0.005)$. No difference was observed in p53 mutation rates according to grades individually $(\mathrm{p}=0.257)($ Table 4$)$. 
Table 4 Distribution of molecular/genetic parameters in diagnostic and grading groups classified according to the WHO 2016 tumor classification

\begin{tabular}{|c|c|c|c|c|c|c|}
\hline & $\mathbf{n}$ & $\%$ & $\begin{array}{c}\text { IDH } \\
\text { mutant (\%) }\end{array}$ & $\begin{array}{c}\text { ATRX } \\
\text { mutant (\%) }\end{array}$ & $\begin{array}{c}1 p / 19 q \\
\text { codeleted (\%) }\end{array}$ & $\begin{array}{c}\text { p53 } \\
\text { mutant (\%) }\end{array}$ \\
\hline IDHm, 1p/19q codeleted, oligodendroglioma & 40 & 17.9 & $40(100)$ & $5(12.5)$ & $40(100)$ & $12(30)$ \\
\hline IDHm, 1p/19q intact, astrocytoma & 42 & 18.8 & $42(100)$ & $24(57.1)$ & $0(0)$ & $30(71.4)$ \\
\hline IDHwt astrocytoma & 11 & 4.9 & $0(0)$ & $5(45.5)$ & $0(0)$ & $7(63.6)$ \\
\hline IDHm GBM & 19 & 8.5 & $19(100)$ & $12(63.2)$ & $0(0)$ & $13(68.4)$ \\
\hline IDHwt GBM & 112 & 50 & $0(0)$ & $13(11.6)$ & $0(0)$ & $52(46.4)$ \\
\hline Grade II & 64 & 28.6 & $58(90.6)$ & $27(42.2)$ & $27(42.2)$ & $33(51.6)$ \\
\hline Grade III & 29 & 12.9 & $24(82.8)$ & $7(24.1)$ & $13(44.8)$ & $16(55.2)$ \\
\hline Grade IV & 131 & 58.5 & 19 (14.5) & $25(19.1)$ & $0(0)$ & 65 (49.6) \\
\hline Total & 224 & 100 & $101(45.1)$ & 59 (26.3) & 40 (17.9) & $114(50.9)$ \\
\hline
\end{tabular}

IDH: Isocitrate dehydrogenase; ATRX: Alpha-thalassemia X-linked mental retardation; IDHm: IDH mutant; IDHwt: IDH wildtype; GBM: Glioblastoma

Table 5 PFS and OS data of diagnostic and grading groups

\begin{tabular}{|c|c|c|c|c|c|c|}
\hline & \multicolumn{3}{|c|}{ PFS } & \multicolumn{3}{|c|}{ OS } \\
\hline & Mean & SD & $\begin{array}{c}\text { Median } \\
\text { (min-max) }\end{array}$ & Mean & SD & $\begin{array}{c}\text { Median } \\
\text { (min-max) }\end{array}$ \\
\hline IDHm, 1p/19q codeleted, oligodendroglioma & 53.08 & 44.51 & $35.50(4-153)$ & 65.33 & 49.707 & $47.50(4-159)$ \\
\hline IDHm, 1p/19q intact, astrocytoma & 42.98 & 34.25 & $30.50(4-132)$ & 55.62 & 47.1 & $32(4-156)$ \\
\hline IDHwt astrocytoma & 25.27 & 24.15 & $15(2-72)$ & 34.36 & 40.27 & $15(2-135)$ \\
\hline IDHm GBM & 27.16 & 37.4 & $17(2-167)$ & 41.74 & 43.02 & $28(2-178)$ \\
\hline IDHwt GBM & 12.65 & 12.69 & $10(1-86)$ & 16.5 & 16.69 & $12.50(1-106)$ \\
\hline Grade II & 45.37 & 40.89 & $28(4-153)$ & 53.64 & 47.46 & 30.5 (4-159) \\
\hline Grade III & 44.9 & 34.28 & $35(2-120)$ & 65.31 & 49.04 & $40(2-156)$ \\
\hline Grade IV & 14.76 & 18.91 & $10(1-167)$ & 20.16 & 23.95 & $14(1-178)$ \\
\hline Total & 27.41 & 32.48 & $15(1-167)$ & 35.57 & 40.26 & $19(1-178)$ \\
\hline
\end{tabular}

PFS: Progression-free survival; OS: Overall survival; IDH: Isocitrate dehydrogenase; IDHm: IDH mutant; IDHwt: IDH wildtype; GBM: glioblastoma; SD: Standard deviation

\section{Survival Results}

The follow-up duration was defined as the period from diagnosis until death or the end of the follow-up for whatever reason. Surgical results were grouped into three according to the results of the first surgery. Total resection, gross total resection (GTR), and subtotal resection rate were $5.8 \%, 85.7 \%$, and $8.5 \%$, respectively, with no significant difference in surgical outcomes among the diagnostic $(\mathrm{p}=0.496)$ and grade $(\mathrm{p}=0.951)$ groups. Survival was evaluated according to two parameters: Progression-free survival (PFS) and overall survival (OS).

By the end of the study period, a total of 85 (37.9\%) patients had died with a mean PFS and OS of 27.4 ( \pm 32.5 ; median 15 [1-167]) months and 35.6 ( \pm 40.3 ; median 19 [1-178]) months, respectively (Table 5).

Survival analysis showed no significant association between tumor lateralization and PFS $(\mathrm{P}=0.680)$ and
OS ( $\mathrm{p}=0.625)$. The Kaplan-Meier curves are presented in Figure $1 \mathrm{a}$ and $\mathrm{b}$.

After comparing PFS among the diagnostic groups using binary log-rank analysis, our findings showed that the Oligo group had a significantly lower PFS than the Gbm, GbmW, and AW groups $(\mathrm{p}=0.000)$. Moreover, the Ast group had a better PFS than the Gbm and GbmW groups $(\mathrm{p}=0.000)$. No significant difference in PFS was noted between the Oligo and Ast groups ( $\mathrm{p}=0.527)$; between the Gbm and GbmW groups ( $\mathrm{p}=0.124)$; and between the GbmW and AW groups ( $\mathrm{p}=0.133$ ) groups (Fig. 1c).

OS comparison among the diagnostic groups revealed that the Oligo group had a significantly longer OS than the Gbm, GbmW, and AW groups ( $\mathrm{p}=0.000$ ). Moreover, the Ast group had a longer OS than the Gbm and GbmW groups $(\mathrm{p}=0.000)$, whereas the $\mathrm{Gbm}$ group had a longer OS than the GbmW group $(\mathrm{p}=0.021)$. 

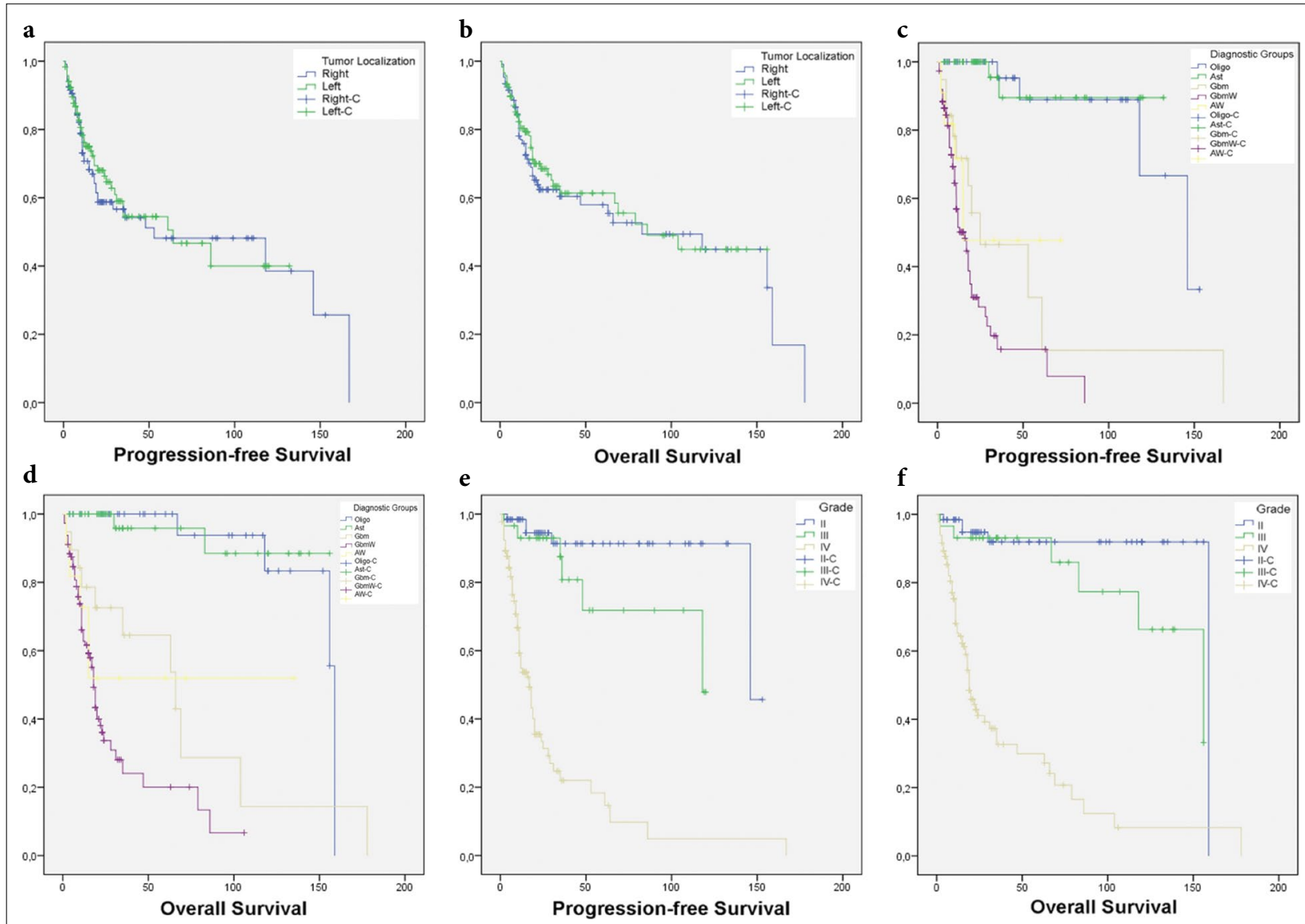

Fig. 1. Kaplan-Meier curves show the relation of (a) Lateralization on progression-free survival; (b) Tumor lateralization on overall survival; (c) The glioma diagnostic groups regarding progression-free survival; (d) Glioma diagnostic groups regarding overall survival; (e) Glioma grading groups regarding progression-free survival; and (f) Glioma grading groups regarding overall survival.

Oligo: oligodendroglioma; Ast: astrocytoma; Gbm: glioblastome multiforme; GbmW: IDH wildtype (IDHwt) glioblastome multiforme; AW: IDHwt astrocytoma; C: censored.

No significant difference in OS was noted between the Gbm and AW ( $p=0.989)$ groups and between the GbmW and AW ( $\mathrm{p}=0.185$ ) groups (Fig. 1d).

PFS comparison among the grade groups showed no difference between those with grades III and II disease $(\mathrm{p}=0.078)$ but a significantly shorter PFS in those with grade IV disease than those with grade II $(\mathrm{p}=0.000)$ and grade III ( $p=0.000)$ disease (Fig. 1e). Moreover, those with grade IV disease had a shorter OS than those with grade II $(\mathrm{p}=0.000)$ and grade III $(\mathrm{p}=0.000)$ disease. No difference in OS was found between those with grade II and III disease ( $\mathrm{p}=0.114)$ (Fig. 1f).

\section{Discussion}

Although gliomas have a relatively low incidence, their heavy socioeconomic burden warrants investiga- tion into their etiology. Developments in the field of neuro-oncology have promoted better survival among patients with primary brain cancer, with the 5-year survival reaching up to $33.7 \%$.[4] These developments have necessitated epidemiological studies to evaluate several genetic and nongenetic environmental factors as possible risk factors.

Studies have shown that primary malignant brain tumor incidence and mortality rates were higher in men than in women, albeit not significantly.[1,4] Of note, gender differences were much less pronounced among patients with low-grade gliomas. Although the present study included more males than females, the difference was not significant.

Family history has been one of the most studied factors in oncogenesis, with approximately $5 \%-10 \%$ of patients with glioma having a family history of glioma. 
[5] Studies have shown a 2- to 3-fold increase in the risk of glioma for first-degree relatives in such populations. $[1,4]$ The results of this study were in accordance with some studies that reported no difference.[6]

Ionizing radiation has been the most validated risk factor for brain and CNS tumors in general.[7] Although the INTERPHONE study, which evaluated 13 countries, 16 centers, and 10,500 individuals, could not reach a definitive conclusion regarding the association between mobile phone use and an increased risk of gliomas, their results underlined the increased risk of ipsilateral and temporal gliomas at the highest exposure level.[8] The current study showed that the Oligo and Ast groups had a higher cumulative mobile phone use than the GbmW group. This may be attributed to age difference, considering that the GbmW group comprised older patents. Moreover, considering grade groups separately, daily mobile phone use was significantly higher in those with grade II gliomas. However, we believe that variability in what is considered "mobile phone usage" (calls, mobile games, social media, and other) may reduce the standardization and reliability of data.

Studies have evaluated relationships between gliomas and anthropometric parameters, even at birth. Moore et al.s[9] study showed that individuals with a height of $\geq 1.9 \mathrm{~m}$ had twice the glioma risk (2.12 relative risk). The present study revealed that patients with grade IV tumors had a significantly higher BMI than those with grade II tumors. Furthermore, reports have shown that sports and physical activity initiated at an early age, which improve insulin resistance, may decrease the risk of glioma by $36 \%$. The Gbm and GbmW groups included in the present study participated in sports less frequently than the Ast and Oligo groups. All these findings may be considered as risk factors attributed to modifiable daily activities and habits.

Eating habits may be one of the determining factors for glioma risk. While processed red meat rich in nitrosamines and a low antioxidant diet have been associated with an increased risk for developing gliomas, other studies have shown no such relationship.[10] Meanwhile, in the current study, the patients reported a balanced diet comprising all three basic food groups, with no significant difference among the groups. However, this might be regarded as a self-report-based bias, and more objective data are needed.

After evaluating 182 patients with low-grade glioma, Chaichana et al.[11] reported that persistent hyperglycemia was significantly associated with decreased survival, increased recurrence, and increased malignant transformation. Likewise, the present study revealed that pre-di- agnosis blood glucose elevation was significantly higher among the GbmW and grade IV groups.

Varying results regarding the negative or positive association between coffee, tea, alcohol consumption, or smoking and glioma risk have been published. $[12,13]$ The use of over-the-counter medicine, such as aspirin, and nonsteroidal anti-inflammatory drugs, have been the most researched drug groups regarding glioma risk.[14] However, similar to that observed in the present study, any such association between these factors and glioma risk might be achieved in selected special large homogenous populations.

The relationship between localization and tumor molecular biology has been previously studied. Studies have found that IDHm diffuse low-grade gliomas and $1 p$ and/or $19 q$ deletion were mostly detected in the anterior portion of the brain, particularly in the frontal lobe, but rarely in the insula.[15] The present study found that ATRX mutations were predominantly observed in left-sided tumors, whereas $1 \mathrm{p} / 19 \mathrm{q}$ codeletion was higher in right-sided tumors. However, no significant survival difference in tumor lateralization and localization was found among the diagnostic groups. We believe that such findings may guide further studies to reveal such associations.

Studies have found that surgical resection rates were directly related to survival among those with low-grade gliomas, although molecular variables were not compared.[16] In a study involving low-grade glial tumors, Delev et al.[17] found that GTR did not significantly affect median OS among those with IDHm and $1 \mathrm{p} / 19 \mathrm{q}$ codeletion who received adjuvant treatment after biopsy. The present study found no significant difference regarding molecular profiles with respect to the resection rates. Nevertheless, instead of self-reported record-based resection rates, determining radiologically confirmed resection rates will yield more reliable results.

FISH has been the preferred molecular testing method for detecting $1 \mathrm{p} / 19 \mathrm{q}$ codeletion at most centers. However, FISH may only target one locus in each chromosome arm, which may be considered very restrictive. In this respect, reports have shown that evaluating $1 \mathrm{p} / 19 \mathrm{q}$ codeletion using FISH may lead to "false positive" results.[18] After studying molecular markers using different techniques, Ballester et al.[19] concluded that $1 \mathrm{p} / 19 \mathrm{q}$ testing may not be required in gliomas with classical GBM properties. By contrast, ATRX loss is a characteristic of astrocytomas and is usually associated with $1 \mathrm{p} / 19 \mathrm{q}$ codeletion. The detection of cases with impaired association led to questions regarding the status of ATRX as a marker.[19] Unlike the aforementioned 
study, Huse et al.[20] suggested that ATRX loss and $1 \mathrm{p} / 19 \mathrm{q}$ codeletion may be completely separate entities, with any association between these two genetic conditions considered the rarely observed "real" mixed glioma. While almost all IDHm and $1 \mathrm{p} / 19 \mathrm{q}$ intact gliomas are accompanied by ATRX loss, intact ATRX has also been reported.[21] All these conflicting results indicate the complexity of the process and the problematic issues regarding the current molecular glioma classification. In other words, "false positive" molecular markers consist a major classification issue and methods that reflect the requirements of the WHO classification may themselves be inadequate to establish a profile with adequate sensitivity. Therefore, more sensitive, selective, and practical techniques are needed to establish reliable molecular profiles and tumor classifications.

The POLA cohort study, which compared the 2007 and 2016 WHO classification in 1041 patients, argued that the WHO 2016 classification system was able to establish a clearer differential prognosis.[22] In their cohort study, Rogers et al.[23] found a close relationship among nuclear immunostaining, ATRX loss, and IDH mutations and subsequently observed no ATRX loss in tumors with $1 \mathrm{p} / 19 \mathrm{q}$ codeletion. This again reiterates the idea that $1 \mathrm{p} / 19 \mathrm{q}$ testing may not be required in cases without ATRX loss. However, our results showed that both genetic anomalies may coexist. Moreover, while IDH mutations have been found to be proportional to TP53 overexpression, a negative correlation was observed between TP53 overexpression and chromosome $1 \mathrm{p} / 19 \mathrm{q}$ coding. Scheie et al.[24] reported that tumor grade and $1 \mathrm{p} / 19 \mathrm{q}$ status were independent prognostic factors in histologically confirmed oligodendroglia cases. Pekmezci et al.[25] reported that tumor grade did not affect survival in the cases of molecularly defined oligodendrogliomas. CDKN2A homozygous deletion, RB1 deletion or mutation, and CDK4 amplification were more important markers of prognosis and have been shown to be associated with shorter survival.[3] Unfortunately, the aforementioned markers cannot be routinely evaluated in all laboratories worldwide. This is another major issue regarding the suggested classification system.

The Consortium to Inform Molecular and Practical Approaches to CNS Tumor Taxonomy of the International Neuropathology Community has published directives for developments until the announcement of the 2021 WHO classification.[26] The notion of not elsewhere classified had been proposed for cases that could not be included in any defined group despite having a confirmed molecular profile.[27] The NOS group was excluded from the present evaluation, considering that such a situation may compromise all advantages of the 2016 WHO classification. This significantly reduced our sample size. Moreover, some examinations were suggested to be performed using sequencing. [28] Our study also supports the extent of data obscurity and molecular biomarker interaction. We believe that all these suggestions may provide clues regarding the future classifications.

Although the WHO 2016 classification considers molecular markers to play an important role, potentially serious technical concerns still remain. The fourth and even the last fifth (2021) edition of the WHO Classification include examinations that may take longer to process in laboratories with limited resources. Therefore, this may be considered to have increased the laboratory workload and expenses, which is significant considering that most countries continue to experience problems regarding financing and kit supply. Technically, standardizing the evaluation of molecular biomarkers for gliomas is still difficult owing to several factors, such as lack of kits, lack of funds, and insufficient scientific algorithms at the laboratories. For instance, IDH sequencing is not routinely performed among cases wherein IDH mutation is not detected by immunohistochemistry. Such issues may highlight problems related to the fourth edition of the WHO classification as well as the possible issues experienced globally. For instance, variations in the reported variant frequency of the PCR system may be present in cases where no clinically significant (actionable) mutation can be detected in the IDH gene region according to the current literature, which would promote lower reliability compared with standardized results.

The latest WHO Classification $\left(5^{\text {th }}\right.$ edition, 2021) of tumors of the CNS that was published recently underlined that the so-called "hybrid taxonomy" is likely only an intermediate stage to an even more precise future classification.[3] Even this updated classification was defined as a "work in progress" regarding the evolution of CNS tumor classification.[3] All these conclusions support our evidence-based suggestions regarding the necessity of more practical and accessible classification system.

Some limitations of this study are worth noting. The present study evaluated and discussed as many potential risk factors as possible regarding glioma etiology. Studying such factors individually and in large controlled randomized populations may undoubtedly provide more detailed and accurate results. By contrast, the absence of a second central system for controlling pathological specimens and molecular data in most studies may cast doubt on the reliability of the 
data. Performance is another important factor affecting survival and should be included in various scales, such as the prospective Karnofsky performance score. Unfortunately, no parameter for assessing performance was used in this study.

\section{Conclusion}

Many factors, particularly high blood glucose levels, sedentary lifestyle, and radiofrequency electromagnetic field exposure, appear to have a relationship with glioma etiology. The WHO CNS tumor classification is a product of a dynamic process and is updated regularly, providing more meticulous diagnosis and formation of biologically and prognostically significant entities. However, our results showed that there is a major heterogeneity and lack of standardized efficient procedures that may interfere with reliable standard molecular results. Routinely used methods that reflect the requirements of the latest WHO classification may themselves be inadequate to establish a reliable sensitivity. Moreover, the development of more practical and accessible methods for identifying such markers in addition to standardized, rapid, and reliable methods for testing multiple markers at an acceptable cost is urgently needed.

Acknowledgments: The authors wish to thank Sabriye Tosunoglu for their help in data collection and patient followup. The authors appreciate the support of Erdem A, Caglar S, Savas A, Unlu A, Attar A, Tuna H, Kahilogullari G, Bozkurt M, Dogan I, Ozgural O, and Eroglu U. The authors also appreciate the efforts of Nazmiye Kursun for performing statistical analyses.

Peer-review: Externally peer-reviewed.

Conflict of Interest: All authors declared no conflict of interest.

Ethics Committee Approval: The study was approved by The Ankara University Human Research Ethics Committee (No: İ6-301-19, Date: 20/12/2019).

Financial Support: This study has received no financial support.

Authorship contributions: Concept - E.B., H.Ç.U.; Design - E.B., H.Ç.U., N.T., B.T., M.B., Y.G., Y.E.G.; Supervision E.B., H.Ç.U.; Funding - E.B., H.Ç.U.; Materials - E.B., B.T., N.T., M.B., Y.G., H.Ç.U.; Data collection and/or processing - E.B., N.T., B.T., M.B.; Data analysis and/or interpretation E.B., N.T., Y.G., H.Ç.U.; Literature search - E.B., N.T., Y.E.G.; Writing - E.B.; Critical review - H.C.U., Y.G.

\section{References}

1. Ostrom QT, Gittleman H, Fulop J, Liu M, Blanda R, Kromer C, et al. CBTRUS statistical report: primary brain and central nervous system tumors diagnosed in the United States in 2008-2012. Neuro Oncol 2015;17(Suppl 4):iv1-iv62.

2. Louis DN, Ohgaki H, Wiestler OD, Cavenee WK. WHO classification of tumours of the central nervous system. Revised $4^{\text {th }}$ ed. Lyon: IARC; 2016. p. 10-122.

3. Louis DN, Perry A, Wesseling P, Brat DJ, Cree IA, Figarella-Branger D, et al. The 2021 WHO classification of tumors of the central nervous system: a summary. Neuro Oncol 2021;23(8):1231-51.

4. Howlader N, Noone AM, Krapcho M. SEER cancer statistics review, 1975-2011. National Cancer Institute. Available at: http://seer.cancer.gov/csr/1975_2011. Accessed Jul 11, 2021.

5. Goodenberger ML, Jenkins RB. Genetics of adult glioma. Cancer Genet 2012;205(12):613-21.

6. Sadetzki S, Bruchim R, Oberman B, Armstrong GN, Lau CC, Claus EB, et al. Description of selected characteristics of familial glioma patients - results from the Gliogene Consortium. Eur J Cancer 2013;49(6):133545.

7. Linet MS, Slovis TL, Miller DL, Kleinerman R, Lee C, Rajaraman $\mathrm{P}$, et al. Cancer risks associated with external radiation from diagnostic imaging procedures. CA Cancer J Clin 2012;62(2):75-100.

8. Grell K, Frederiksen K, Schüz J, Cardis E, Armstrong $B$, Siemiatycki J, et al. The intracranial distribution of gliomas in relation to exposure from mobile phones: analyses from the INTERPHONE study. Am J Epidemiol 2016;184(11):818-28.

9. Moore SC, Rajaraman P, Dubrow R, Darefsky AS, Koebnick C, Hollenbeck A, et al. Height, body mass index, and physical activity in relation to glioma risk. Cancer Res 2009;69(21):8349-55.

10. Wang P, Hou C, Li W, Zhou D. Dietary nitrite and nitrate is not associated with adult glioma risk: a meta analysis. Int J ClinExp Med 2016;9:8334-40.

11. Chaichana KL, McGirt MJ, Woodworth GF, Datoo G, Tamargo RJ, Weingart J, et al. Persistent outpatient hyperglycemia is independently associated with survival, recurrence and malignant degeneration following surgery for hemispheric low grade gliomas. Neurol Res 2010;32(4):442-8.

12. Gonzalez CA, Riboli E. Diet and cancer prevention: Contributions from the European Prospective Investigation into Cancer and Nutrition (EPIC) study. Eur J Cancer 2010;46(14):2555-62.

13. Li HX, Peng XX, Zong Q, Zhang K, Wang MX, Liu $\mathrm{YZ}$, et al. Cigarette smoking and risk of adult glioma: a meta-analysis of 24 observational studies involving 
more than 2.3 million individuals. Onco Targets Ther 2016;9:3511-23.

14. Amirian ES, Ostrom QT, Armstrong GN, Lai RK, $\mathrm{Gu}$ X, Jacobs DI, et al. Aspirin, NSAIDs, and Glioma Risk: Original data from the glioma international casecontrol study and a meta-analysis. Cancer Epidemiol Biomarkers Prev 2019;28(3):555-62.

15. Cancer Genome Atlas Research Network, Brat DJ, Verhaak RG, Aldape KD, Yung WK, Salama SR, et al. Comprehensive, integrative genomic analysis of diffuse lower-grade gliomas. N Engl J Med 2015;372(26):2481-98.

16. Eseonu CI, Eguia F, ReFaey K, Garcia O, Rodriguez FJ, Chaichana $\mathrm{K}$, et al. Comparative volumetric analysis of the extent of resection of molecularly and histologically distinct low grade gliomas and its role on survival. J Neurooncol 2017;134(1):65-74.

17. Delev D, Heiland DH, Franco P, Reinacher P, Mader I, Staszewski O, et al. Surgical management of lowergrade glioma in the spotlight of the 2016 WHO classification system. J Neurooncol 2019;141(1):223-33.

18. Clark KH, Villano JL, Nikiforova MN, Hamilton RL, Horbinski C. $1 \mathrm{p} / 19 \mathrm{q}$ testing has no significance in the workup of glioblastomas. Neuropathol Appl Neurobiol 2013;39(6):706-17.

19. Ballester LY, Huse JT, Tang G, Fuller GN. Molecular classification of adult diffuse gliomas: conflicting IDH1/IDH2, ATRX, and 1p/19q results. Hum Pathol 2017;69:15-22.

20. Huse JT, Diamond EL, Wang L, Rosenblum MK. Mixed glioma with molecular features of composite oligodendroglioma and astrocytoma: a true "oligoastrocytoma"?. Acta Neuropathol 2015;129(1):151-3.

21. Reuss DE, Sahm F, Schrimpf D, Wiestler B, Capper D, Koelsche C, et al. ATRX and IDH1-R132H immunohistochemistry with subsequent copy number analy- sis and IDH sequencing as a basis for an "integrated" diagnostic approach for adult astrocytoma, oligodendroglioma and glioblastoma. Acta Neuropathol 2015;129(1):133-46.

22. Tabouret E, Nguyen AT, Dehais C, Carpentier C, Ducray F, Idbaih A, et al. Prognostic impact of the 2016 WHO classification of diffuse gliomas in the French POLA cohort. Acta Neuropathol 2016;132(4):625-34.

23. Rogers TW, Toor G, Drummond K, Love C, Field K, Asher R, et al. The 2016 revision of the WHO Classification of Central Nervous System Tumours: retrospective application to a cohort of diffuse gliomas. J Neurooncol 2018;137(1):181-9.

24. Scheie D, Meling TR, Cvancarova M, Skullerud K, Mørk S, Lote K, et al. Prognostic variables in oligodendroglial tumors: a single-institution study of 95 cases. Neuro Oncol 2011;13(11):1225-33.

25. Pekmezci M, Rice T, Molinaro AM, Walsh KM, Decker $\mathrm{PA}$, Hansen $\mathrm{H}$, et al. Adult infiltrating gliomas with WHO 2016 integrated diagnosis: additional prognostic roles of ATRX and TERT. Acta Neuropathol 2017;133(6):1001-16.

26. Yeaney GA, Brat DJ. What every neuropathologist needs to know: Update on cIMPACT-NOW. J Neuropathol Exp Neurol 2019;78(4):294-6.

27. Louis DN, Wesseling P, Paulus W, Giannini C, Batchelor TT, Cairncross JG, et al. cIMPACT-NOW update 1: Not Otherwise Specified (NOS) and Not Elsewhere Classified (NEC). Acta Neuropathol 2018;135(3):4814.

28. Mellai M, Annovazzi L, Senetta R, Dell'Aglio C, Mazzucco M, Cassoni P, et al. Diagnostic revision of 206 adult gliomas (including 40 oligoastrocytomas) based on ATRX, IDH1/2 and 1p/19q status. J Neurooncol 2017;131(2):213-22. 